\title{
On Compaction Characteristics and Particle Breakage of Soil-aggregate Mixture
}

\author{
Xi Chang XU ${ }^{1, a}$, Shan Xiong CHEN ${ }^{1, b}$ and Ling Fa JIANG ${ }^{1, c}$ \\ ${ }^{1}$ State Key laboratory of Geomechanics and Geotechnical Engineering, Institute of Rock and Soil \\ Mechanics, Chinese Academy of Sciences, Wuhan 430071, PR China \\ axcxu@whrsm.ac.cn, ${ }^{\mathrm{b}} \mathrm{sxchen@whrsm.ac.cn,}{ }^{\mathrm{C}}$ Ifjiang@whrsm.ac.cn
}

Keywords: Soil-aggregate mixture, Compaction properties, Dry density, Particle breakage

\begin{abstract}
Based on a certain big site preparation project, the method to determine the dry density of filler for soil-aggregate mixture has been studied, and the characteristics of particle breakage after vibration is discussed. The results show that the surface vibration compaction method to determine the maximum dry density with mixture is suitable to soil-aggregate mixture. Considering the compaction factor of 0.94 , the dry density control standard deducing from the maximum dry density is close to the projected field compaction test results. The particle breakage of soil-aggregate mixture during vibration is close to $20 \%$, which shows that the particle breakage is significant. This study may have certain significance to similar projects.
\end{abstract}

\section{Introduction}

In recent years, the key construction projects in the central and western regions of China are having been more and more, such as the highways, railways, hydroelectricity, airports and nuclear power, which are mostly in mountainous area, facing the problems of large-scale ground leveling. In line with the principle of local materials and pollution reduction, the filler is mainly filled with excavation blasting stone, containing a small amount of coverage, which belonging to the earth and stone mix filler problems. In order to facilitate research, many scholars use the generalized definition of soil-aggregate mixture. Along with the improvement of the industry designation level, construction technology and the geotechnical tests level, the tolerated particle size of soil-aggregate mixture filler is increasingly growing, far beyond the range of coarse grained soil particle size, which belongs to the giant grain group category [1]. Particularly in some hydroelectricity projects, the maximum diameter of packing is up to $1 \mathrm{~m}$.

Before the largely start of the filler construction, the filler control standards must be fixed, which mainly refer to the filler dry density. Generally control dry density is definite after the maximum dry density is determined by indoor test. Then determine the fill control dry density through combining between factor of compaction and field rolling test.

The field construction parameters are often determined with combination of the rolling test in some roads, dams, large field flat engineering project filler. And then the large area construction is started, result in good achievements. In the field rolling test research, some experts have put forward the soil compaction quality should be controlled mainly to the settlement difference [2], based on the discussion of the compaction mechanism of coarse-grained soil in the high embankment reclamation engineering, and the different construction process parameters effect on construction effects, such as packing gradation, moisture content and shop, rolling machine, the thickness of the soil compaction quantities and so on. And other scholars have also studied the field rolling test and the quality control standards, and have obtained some significant conclusions [3, 4].

The soil particle breakage is defined as the phenomenon that the structure of soil particles will be destroyed or damaged in the external load, and will split into equal or unequal amounts of particle size. However, soil particles are not compressed and broken based from classical soil mechanics. Granular soil particles broken engineering background is that the growing construction of international high buildings in the 1960's, caused the large load of the foundation and the particle 
breaking of quartz sand, gravel. In recent years, the effects of particle breaking are more and more remarkable with the construction of the large projects, especially the widely use of the soil-aggregate mixture. For example in the construction of Three Gorges project, the broken rate of filler materials weathered granite material sometimes reached $20 \%$. And at present, people pay more attention to particle breakage phenomenon, especially the relationship between the particle breaking and mechanical characteristic. Zhang has presented study status of this paper comprehensively at home and abroad [5]. Yang guang have studied the particle breakage phenomenon under different stress path aggregates, and have found that the influence of stress path to aggregates of strength characteristics is not significant, but the improvement of the degree of particle breakage will decrease the peak internal friction angle [6]. Shi Xiu Song have studied the particle breakage fractal features of rock fill materials and have found that broken fractal dimension reflects the even degree such as the size and distribution of the particles breakage. The bigger fractal dimension is, the larger quantity of the particles breakage is [7].

Taking a large field flat project as background, combining with the rolling test, this paper analyzes the soil-aggregate mixture compaction characteristic and the indoor particle breaking characteristics, and has obtained the certain common conclusion to help establish and perfect the relevant industry sectors in the corresponding standard, expand procedure and promotion of soil-aggregate mixture in the application.

\section{Engineering background}

The project is a large-scale project mountain flat. Its excavation is about 18.29 million $\mathrm{m} 3$ conditions. Its filler is about 21.03 million $\mathrm{m}^{3}$, and the filler height is mostly more than $20 \mathrm{~m}$. The packing has complex lithology packing, and weathering degree is not uniform. The packing is comprised with four kinds, including the construction area packing as mixture of II, III kind. The II kind of material is the weak weathered gray matter conglomerate. The III kind of material is the strong and the moderately weathered conglomerate. All of them are made into the small broken stone through blasting, solution and other method. The construction area filler quality is the key point, and it is required that coarse material contents of mixture of II, III kind are at $70 \%$, and its maximum diameter is no more than $300 \mathrm{~mm}$. Energetically, particles that size $>5 \mathrm{~mm}$ are defined as coarse material, and size $<5 \mathrm{~mm}$ are defined as fine material.

\section{Laboratory experiment}

Experimental designs. Many experts have been carrying out theoretical and experimental studies in the maximum dry density of soil-aggregate mixture. Currently, as the theoretical research is lagging behind, the main method is through experiment. The experimental study included direct and indirect. The direct method is to enhance the performance of the instrument to determine the maximum dry density. Since it is limited by the performance of equipment and the range of particle size, the research progress of this method is slow. Indirect method used the existing test conditions. To extrapolate the maximum dry density of the filler prototype gradation, this method is based on measuring the relationship of the maximum dry density and particle size of coarse grained soil which can be measured in the size range. In recent years, the indirect method is developing well. Such as Yanwen Shi proposed the extension of a series of similar gradation[8], Shuyu Tian's Asymptote assisted fitting[9], Qingguo Guo’s Three-point approximation of the Determination [10].

This paper sampled from the field and used the method of the extension of a series of similar gradation to determine the maximum dry density of the packing of the project.

Soil samples preparation. Taking into account the variability of the packing, we sample from the loose overlay directly and excavate test pits in the construction of the two different filler area. The diameter of these pits range at $1 \mathrm{~m}$ and the depth is the thickness of the loose overlay. The sample less than $60 \mathrm{~mm}$ is shipped back to the laboratory from screening in the field and labeled 1\# and 2\# (all of them are mixture) respectively. 
Soil samples will be recovered in the outdoor drying and air-dried stopped when the water content close to the normal sample drying. Then, air-dried soil samples are used to screen test. $2 \mathrm{~mm}$ sieved soil less than $10 \%$ of the sample's total mass, and therefore omit the fine sieve analysis. Original grain size distribution curve is shown in Fig. 1.

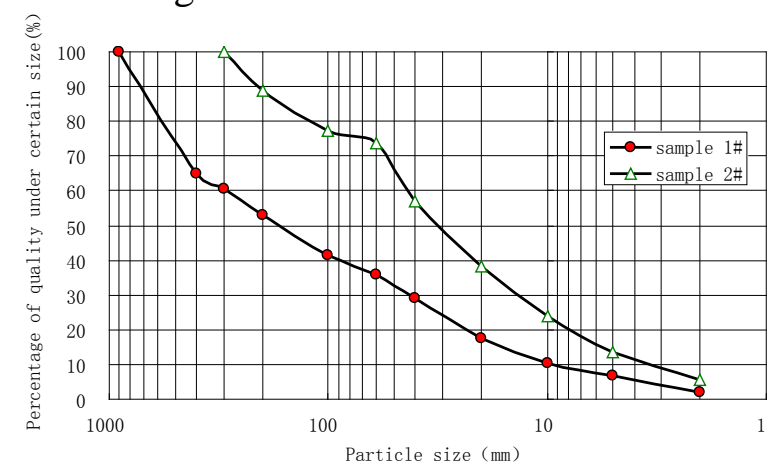

Fig. 1 Original grain size distribution curve for soil sample

According to the result of the partial test, the maximum diameter of sample $1 \#$ dmax $=900 \mathrm{~mm}$, nonuniform coefficient of the whole material $C_{U}=30$, curvature coefficient $C_{C}=0.06$. It shows that $1 \#$ is belonging to bad gradation. The maximum diameter of sample $2 \#$ dmax $=300 \mathrm{~mm}$, nonuniform coefficient of the whole material $C_{U}=12.8$, curvature coefficient $C_{C}=1.4$. It shows that sample $2 \#$ is belonging to good gradation.

Using drying method to measure the water content of two samples' fines (below 5mm sieved) and coarse material (above $5 \mathrm{~mm}$ sieved) respectively. The fines material of sample $1 \#$ and $2 \#$ is $1.39 \%$ and $2.03 \%$ respectively, and the coarse material is $0.76 \%$ and $0.70 \%$ respectively.

Test method. According to the original grain size distribution curve of $1 \#$ and 2\#, content of coarse is large. Rolling process of drainage performance is good, and surface vibratory compaction method is similar to and simpler than the vibrating roller compaction conditions. Sample is not easy separation during vibration compaction so that use surface vibration compactor method for the determination of the maximum dry density. Water-reducing method is close to the actual conditions, so select water-reducing method to test.

The method of similar gradation was prepared to narrow the diameter of a series of model test materials to carry out the compaction test which is based by "Highway geotechnical testing procedures" (JTG E40-2007). The BZYS4212 equipment of surface vibration compactor is used.

A different modulus ratio is determined by the actual packing of the largest particle size. So the modulus of $1 \#$ is 15, 18, 23 and 2\# is 5, 7.5 and 15 respectively. And calculate the grading curve through the corresponding modulus to prepare test soil samples. Each modulus ratio prepared for two parallel samples and test set for 6 minutes.

Test results and analysis. Sample 1 \# and 2 \# sample test results are given in Fig. 2 and Fig. 3.

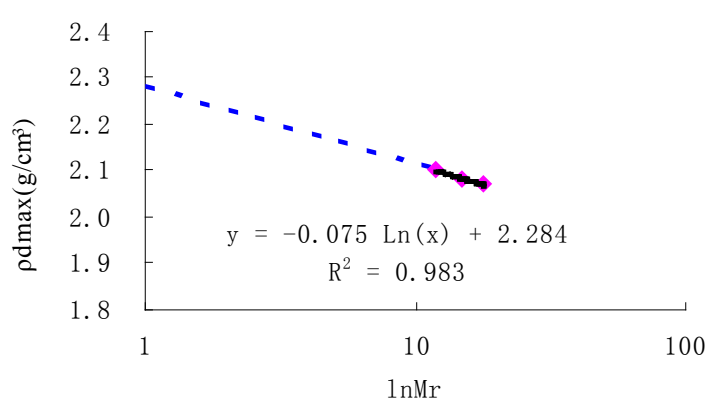

Fig. 2 Relation curves between $\rho_{\mathrm{dmax}}$ and $\ln \mathrm{Mr}$ for $1 \#$ sample

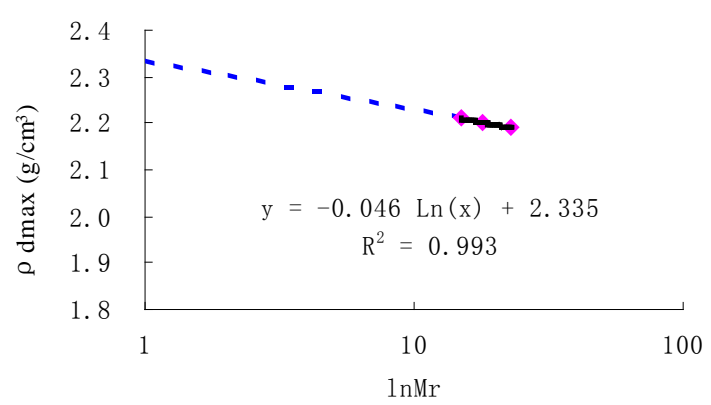

Fig. 3 Relation curves between $\rho_{\text {dmax }}$ and $\operatorname{lnMr}$ for $2 \#$ sample

Through the extension of logarithm, the Original grain size distribution of $1 \#$ and $2 \#$ corresponding to the maximum dry density of $2.34 \mathrm{~g} / \mathrm{cm} 3$ and $2.38 \mathrm{~g} / \mathrm{cm} 3 \mathrm{can}$ be obtained when $\mathrm{Mr}=1$. 
From the laboratory test results, although the two soil samples graded large difference, the maximum dry density is basically the same. It is indicating that the main factor of the gradation is not affect the maximum dry density.

Determination of the filler control standards. During the indoor vibratory compaction test, the construction according to the design requirements for the field compaction test. Select conditions of rolling instrument under which it is intended to meet the design standards and reasonable construction parameters, including the fill thickness, rolled times, walking speed, dry density and etc. Compaction test results can be achieved dry density index is $2.12 \mathrm{~g} / \mathrm{cm}^{3}$.

If the laboratory test maximum dry density as $2.34 \mathrm{~g} / \mathrm{cm}^{3}$, take 0.94 compacting factor of field to consider. So control dry density of $2.20 \mathrm{~g} / \mathrm{cm}^{3}$ is close to the dry density of the field compaction test. It indicates that surface vibration compaction method to determine the aggregate mixture maximum dry density is feasible.

Therefore, designation of the final dry density is $2.12 \mathrm{~g} / \mathrm{cm}^{3}$.

\section{Particle breakage characteristics analysis}

Particle breakage is a complex process which is related to particle size, size distribution, particle shape and particle hardness. Particle breakage most obvious manifestation is the changes of the particle size distribution of the grading curve, which indicates that the coarse aggregates particles fractured in the loading process and the particle size has undergone significant changes. Fig. 4 and, Fig. 5 show that Grain size distribution curve for 1\# sample of 15 and 23 modulus before and after vibration.

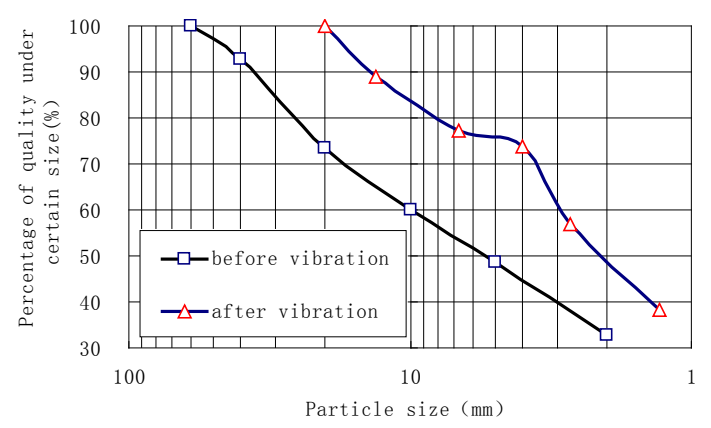

Fig. 4 Grain size distribution curve for

$1 \#$ sample before and after vibration $(\mathrm{Mr}=15)$

It needs a measurement scale of degree of particle breakage when make a quantitative analysis of particle breakage on the strength and deformation characteristics of coarse aggregates. Studies have shown that the relative breaking rate for any given particle size of soil particles content, no matter before or after the test corresponding to the particle size change is included in the calculation of the area and small measurement error does not affect the entire area or relative breaking rate. Relative particle breakage rate reflects the variation of the various particle size of the sample before and after the test and is stable. At home and abroad, the particle breakage of the soil-aggregate mixture is often described by the relative fragmentation rate $\mathrm{Br}$. Initial crushing potential $\mathrm{Bp}$ and after compaction potential $\mathrm{Bm}$ is the area which is enclosed by the grading curve and vertical line of particle size $\mathrm{D}=0.074 \mathrm{~mm}$ respectively. $\mathrm{Br}$ is the ratio of the difference between the two areas to $\mathrm{Bp}$.

Through calculation, $\mathrm{Mr}=15$ and $\mathrm{Mr}=23$ of 1 \# corresponding to the relative breaking rate is $19.9 \%$ and $11.5 \%$. It is indicating that the particles in the process of vibratory compaction broken apparent.

\section{Conclusions}

We can make the following conclusions by the soil-aggregate mixture indoor vibratory compaction test results and particle breakage characteristics analysis: 
1) The surface vibration compaction method to determine the maximum dry density of the soil-aggregate mixture is feasible. If we consider the compaction factor of 0.94 , the filler control standards which is projected by the maximum dry density is close to the field compaction test results according to the projections of the maximum dry density filler control standards.

2) Soil-aggregate mixture in the process of vibratory compaction of particle breakage phenomenon obviously, the largest of nearly $20 \%$. It is indicating that in the study of the process bearing capacity characteristics, deformation characteristics and seepage characteristics should focus on particle breakage.

3) Compaction characteristics of soil-aggregate mixture is affected by many factors. This study is far from comprehensive, and needs to make a further research in the filler control standards, a key factor affecting the compaction characteristics and mechanical properties of particle breakage.

\section{Acknowledgements}

Research presented in this paper was supported by the State Key laboratory of Geomechanics and Geotechnical Engineering (project numbers: SKLQ015 and SKLZ0803).

\section{References}

[1] C. H. Zhu, B. W. Yan, J. M. Liu and Z. H. Wang: Chinese Journal of Rock Mechanics and Engineering. ,vol.26 ( 2007 ), p. 4090 ( in Chinese )

[2] S. L. Qin, S. X. Chen and H. Y. Song: Chinese Journal of Rock Mechanics and Engineering. Vol. 27 ( 2008 ), p. 2101 ( in Chinese )

[3] H. W. Chen: Transportation Science \& Technology, No. 2 (2005), p. 23 (in Chinese)

[4] L. P. LIU and D. Y. Wang: Journal of Chang' an University ( Natural Science Edition ), vol. 26 ( 2006 ), p. 35 (in Chinese)

[5] J. M. Zhang, R. Wang and Y. M. Zhang: Rock and soil mechanics, vol.24 ( 2003 ), p. 661 (in Chinese)

[6] G. Yang, B. Y. Zhang and Y. Z. Yu: Journal of Hydraulic Engineering, vol. 41 ( 2010 ), p. 338 (in Chinese)

[7] X. S. Shi and Z. L. Cheng: Chinese Journal of Rock Mechanics and Engineering, vol. 29 ( 2010 ), p. 3852 (in Chinese)

[8] Y. W. Shi: Chinese civil engineering Journal, vol. 14 ( 1981 ), p.53 (in Chinese)

[9] S. Y. Tian: Chinese Journal of Geotechnical Engineering, vol. 14 ( 1992 ), p. 35 (in Chinese)

[10] G. Q. Guo and Z. C Liu: Journal of hydraulic Engineering. No. 10 ( 1993 ), p. 70 (in Chinese) 